\title{
GA AIDED OPTIMIZATION OF TRANSMITTERS' PARAMETers to Reduce EMF Pollution
}

\author{
ROLICH, T. \& GRUNDLER, D.
}

Abstract: The paper describes method for finding transmitters' parameters for optimal electromagnetic radiation distribution in the observed area. Constraints are protected areas inside the observed area where the strength of the electric field is limited because of the permanent people presence. In the observed area one wish to obtain strength of electric field which is higher than lower limit value to cover the area with enough reception signal strength. The electric field inside protected areas has to be lower than prescribed upper limit. In here described investigation genetic algorithm is used for finding transmitters' parameters constrained by the above mentioned conditions. The investigation is limited to rectangular planar observing area with one, two and three transmitters and with different formation and size of protected areas. The procedure has been repeated and results statistically analyzed. Based on those results it can be concluded that the procedure is applicable and it is justified to continue investigations for more complex and more realistic situations.

Key words: electromagnetic field, genetic algorithm, MATLAB, optimization, transmitter
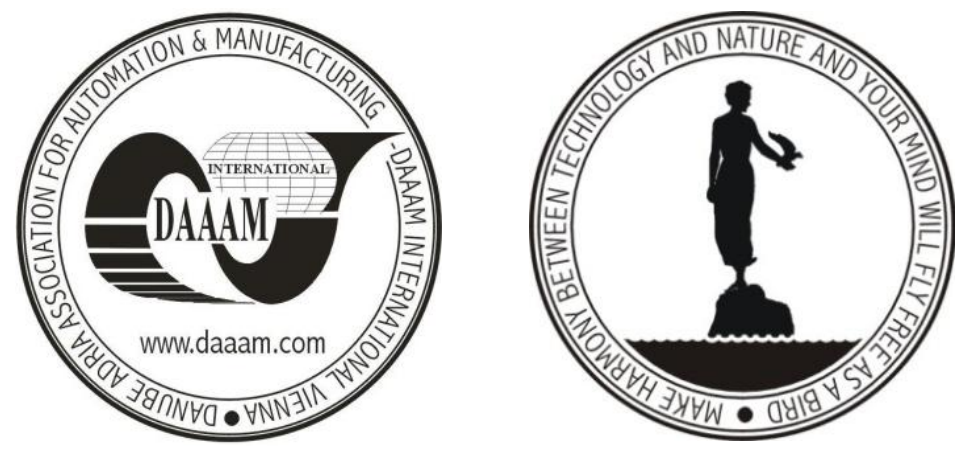

Authors' data: Rolich, T[omislav]; Grundler, D[arko], University of Zagreb, Faculty of Textile Technology, Prilaz baruna Filipovica 28a, HR-10000, Zagreb, Croatia, tomislav.rolich@ttf.hr, darko.grundler@ttf.hr

This Publication has to be referred as: Rolich, T[omislav] \& Grundler, D[arko] (2010). GA Aided Optimization of Transmitters' Parameters to Reduce EMF Pollution, Chapter 61 in DAAAM International Scientific Book 2010, pp. 697-708, B. Katalinic (Ed.), Published by DAAAM International, ISBN 978-3-901509-74-2, ISSN 1726-9687, Vienna, Austria

DOI: 10.2507/daaam.scibook.2010.61 


\section{Introduction}

In the last decade a hazard of electromagnetic environment pollution has been increased, especially in the dense inhabited areas. The reason for that are the allocation of numerous new sources of electromagnetic radiations (GSM, wireless, etc.), especially in cities. The providers of different systems often act independently covering the same area with electromagnetic field. The attempt to adjust parameters of all transmitters on observed area to satisfy the conditions of enough reception signal strength and to minimize electromagnetic field pollution can be complex task.

In this paper investigations of finding transmitters' parameters are described so that two basic criteria are satisfied: the strength of electric field in protected areas (areas of people presence) should be below prescribed level (for total electric field of all transmitters in that area), and the level of transmitters signal should be sufficient for quality level of reception in the whole observed area including protected areas. The transmitters are sometimes located in a direct vicinity of each other (e.g. GSM transmitters in city areas). Because of that it is favourable to determine (or adjust if some of them already exist in the observed area) their parameters so that the pollution of an electromagnetic radiation is minimal while at the same time satisfying their purpose. Most research is concentrated on problem of total coverage of area using minimal number of transmitters, minimal overall cost or maximal signal to noise ratio and do not consider potential health hazards (He, J. et al. 2002; Lin, B. et al. 2007; Mendes, S. P. et al. 2006; Sakthivel, S. \& Suresh, R. 2006).

The observing area is square and inside that area one or more square or rectangular subareas exist. Inside those subareas the level of electromagnetic radiation is limited because of health hazard for people which reside in those areas. These subareas will be called protected areas. Size and number of the protected areas could be different for each observed area. Inside the observing area it is necessary to place the transmitters and to determine their parameters: location and power. All transmitters have circular horizontal radiation diagram i.e. the uniform radiation in all directions. These parameters will be determined using genetic algorithm along with suitable criteria (fitness function) and genetic algorithm parameters.

\section{Investigations}

In this paper described investigations are performed on square observed area with dimensions of $200 \mathrm{~m} \times 200 \mathrm{~m}$ and inside that area, protected areas of square or rectangular shapes are defined. Here described procedure is performed with one, two, three and five protected areas (total of seven cases). In protected areas the strength of the electric field should not exceed upper limit value. Protected areas are places with people presence and because of that the strength of the electric field must be limited to prevent negative influence on people's health.

Transmitters have to accomplish their basic task, i.e. to cover the observed area with a signal strong enough for reception. The strength of the electric field in some point in space can be calculated according to equation (Poljak, D. 2006): 


$$
E=\frac{5.5 \cdot \sqrt{E I R P}}{d} \cdot F(\varphi, \vartheta)
$$

where:

$\mathrm{EIRP}=\mathrm{ERP}+2.15$ - is effectively isotropic radiated power,

ERP - is effectively isotropic radiated power in respect to half-wave dipole,

$\mathrm{F}(\varphi, \theta)$ - is damping factor of the electric field which is a function of deflection angles from direction of maximum in azimuth $\varphi$ and elevation $\theta$,

$\mathrm{d}-$ is distance.

In this paper a damping factor of the electric field is $F(\varphi, \theta)=1$ and procedure applicability in plane has been investigated. The strength of the electric field in two dimensional spaces has been observed so equation for it is:

$$
E=\frac{5.5 \cdot \sqrt{E I R P}}{\sqrt{\left(x-x_{0}\right)^{2}+\left(y-y_{0}\right)^{2}}}
$$

where:

$\mathrm{x}_{0}$ - is coordinate of transmitter location in $\mathrm{x}$-axis direction and

$\mathrm{y}_{0}-$ is coordinate of transmitter location in $\mathrm{y}$-axis direction.

For two or more transmitters a total strength of electric field is:

$$
E=\sqrt{\sum_{i=1}^{n} E_{i}^{2}}
$$

In case of two dimensional spaces and for three transmitters:

$$
E=\sqrt{E_{1 x y}^{2}+E_{2 x y}^{2}+E_{3 x y}^{2}}
$$

The strength of the electric field in two dimensional spaces for first, second and third transmitter is:

$$
\begin{aligned}
E_{1 x y} & =\frac{5.5 \cdot \sqrt{E I R P_{1}}}{\sqrt{\left(x-x_{c 1}\right)^{2}+\left(y-y_{c 1}\right)^{2}}} \\
E_{2 x y} & =\frac{5.5 \cdot \sqrt{E I R P_{2}}}{\sqrt{\left(x-x_{c 2}\right)^{2}+\left(y-y_{c 2}\right)^{2}}} \\
E_{3 x y} & =\frac{5.5 \cdot \sqrt{E I R P_{3}}}{\sqrt{\left(x-x_{c 3}\right)^{2}+\left(y-y_{c 3}\right)^{2}}}
\end{aligned}
$$

Optimal transmitters' parameters (locations and powers) have been determined using a genetic algorithm. The program MATLAB with Genetic Algorithm and Direct Search Toolbox has been used for this purpose. The procedure has been verified for observed area with dimensions of $200 \mathrm{~m}$ x $200 \mathrm{~m}$ and seven cases with 
different number, size and shape of protected areas with limited maximal strength of the electric field $E_{\max }=10 \mathrm{~V} / \mathrm{m}$. For one transmitter minimal strength of the electric field regarding signal covering was $\mathrm{E}_{\min }=0.1 \mathrm{~V} / \mathrm{m}$. A complete procedure has been repeated also for the strength of the electric field $E_{\min }=0.5 \mathrm{~V} / \mathrm{m}$. For two transmitters minimal strength of the electric field regarding signal covering was $E_{1 \min }=0.1 \mathrm{~V} / \mathrm{m}$, $\mathrm{E}_{2 \min }=0.1 \mathrm{~V} / \mathrm{m}$. The complete procedure has been repeated also for the strength of the electric field $E_{1 \min }=0.1 \mathrm{~V} / \mathrm{m}$ for first transmitter and $E_{2 \min }=0.5 \mathrm{~V} / \mathrm{m}$ for second transmitter. For three transmitters minimal strength of electric field regarding signal covering was $E_{1 \min }=0.1 \mathrm{~V} / \mathrm{m}, \mathrm{E}_{2 \min }=0.1 \mathrm{~V} / \mathrm{m}, \mathrm{E}_{3 \min }=0.1 \mathrm{~V} / \mathrm{m}$. The complete procedure has been repeated also for the strength of the electric field $E_{1 \min }=0.1 \mathrm{~V} / \mathrm{m}$ for first transmitter, $E_{2 \min }=0.5 \mathrm{~V} / \mathrm{m}$ for second transmitter and $E_{3 \min }=1.0 \mathrm{~V} / \mathrm{m}$ for third transmitter. An ideal situation would be if the strength of the electric field in whole observed area is the same and higher than the minimal strength of the electric field, and simultaneously below the prescribed maximal level in protected areas. In that sense the optimizing criteria (fitness function) has been defined:

$$
f=10 \cdot \frac{E_{1}+E_{2}+E_{3}+E_{4}}{4}+E_{s}
$$

Strengths of the electric field for first transmitter in four corners of observed area are:

$$
\begin{aligned}
& E_{1}=\frac{5.5 \cdot \sqrt{E I R P_{1}}}{\sqrt{\left(x_{\min }-x_{c 1}\right)^{2}+\left(y_{\text {min }}-y_{c 1}\right)^{2}}} \\
& E_{2}=\frac{5.5 \cdot \sqrt{E I R P_{1}}}{\sqrt{\left(x_{\min }-x_{c 1}\right)^{2}+\left(y_{\max }-y_{c 1}\right)^{2}}} \\
& E_{3}=\frac{5.5 \cdot \sqrt{E I R P_{1}}}{\sqrt{\left(x_{\max }-x_{c 1}\right)^{2}+\left(y_{\text {min }}-y_{c 1}\right)^{2}}} \\
& E_{4}=\frac{5.5 \cdot \sqrt{E I R P_{1}}}{\sqrt{\left(x_{\max }-x_{c 1}\right)^{2}+\left(y_{\text {max }}-y_{c 1}\right)^{2}}}
\end{aligned}
$$

$\mathrm{E}_{\mathrm{s}}$ is arithmetic mean of strength of electric field in the whole area.

The fitness function has been chosen based on investigation and testing of different fitness functions and in the end the above mentioned fitness function has been chosen. The strength of the electric field $E_{1}, E_{2}, E_{3}$ and $E_{4}$ is incorporated in fitness function to avoid that genetic algorithm set transmitter location in four corners of observed area with dimensions of $200 \mathrm{~m}$ x $200 \mathrm{~m}$. A tendency to locate transmitter in the corner of the observing area generally satisfy conditions but produce the unnecessary high transmitter power. The above mentioned fitness function has been used for genetic algorithm population's individuals who satisfied the criteria of maximal and minimal strength of electric field. If individual did not satisfy these criteria than its fitness function (fitness is better if value of fitness function is lower) is multiplied with penalty factor. 
The genetic algorithm population's individuals who have not satisfied criteria have been punished with 10 time higher value of fitness function. The above mentioned is valid for one transmitter. For two transmitters (8) is expanded with four members which are strength of electric field $\mathrm{E}_{5}, \mathrm{E}_{6}, \mathrm{E}_{7}, \mathrm{E}_{8}$ in four corners of observed area for second transmitter. For three transmitters (8) is further expanded with eight members which are strength of electric field $\mathrm{E}_{5}, \mathrm{E}_{6}, \mathrm{E}_{7}, \mathrm{E}_{8}$ in four corners of observed area for second transmitter and strength of electric field $E_{9}, E_{10}, E_{11}, E_{12}$ in four corners of observed area for third transmitter. The genetic algorithm parameters in Genetic Algorithm and Direct Search Toolbox are shown in Table 1.

\begin{tabular}{|l|l|}
\hline Parameter & Value/Property \\
\hline Population size & 500 or 1000 or 2000 \\
\hline Number of generation & 100 \\
\hline Selection & Stochastic uniform \\
\hline Crossover & Intermediate \\
\hline Mutation & Uniform \\
\hline Fitness scaling & Proportional \\
\hline Number of elite individuals & 100 \\
\hline Crossover fraction & 0.8 \\
\hline
\end{tabular}

Tab. 1. Genetic algorithm parameters in Genetic Algorithm and Direct Search Toolbox

The genetic algorithm parameters shown in Table 1 have been chosen based on the investigation experiments and experience. In each generation 320 (for one transmitter), 720 (for two transmitters), 1520 (for three transmitters) individuals have been created with a crossover procedure, 80 (for one transmitter), 180 (for two transmitters), 380 (for three transmitters) individuals have been created with a mutation procedure, and 100 (for one, two and three transmitters) individuals are elite individuals (individuals with lowest value of the fitness function from the previous generation).

\section{Results}

For each of mentioned seven cases, the determination of transmitter optimal location and power were performed 15 times and for both different minimal strength of electric field. At the end of 100th generation individuals were checked. Individuals who satisfy criteria were correct individuals, and those who did not satisfy criteria were incorrect individuals. These have been determined for all 15 cases and for all combinations of different minimal strengths of the electric field. The above mentioned procedure has been done for one, two and three transmitters. If ratio between correct individuals and population size is taken as a measure of procedure success, a different procedure success can be observed. According to that criteria the most successful are procedures in 1st, 2nd, 4th and 5th cases and the least successful are procedures in 3rd, 6th and 7th cases. In Table 2 (for first transmitter of two 
transmitters) and Table 3 (for second transmitter of two transmitters) best individuals from last generation are presented from all 15 runs for determination of transmitter optimal location and power for all seven cases and for minimal strength of the electric field $\mathrm{E}_{1 \mathrm{~min}}=0.1 \mathrm{~V} / \mathrm{m}$ and $\mathrm{E}_{2 \min }=0.1 \mathrm{~V} / \mathrm{m}$. In Table 4 (for first transmitter of two transmitters) and Table 5 (for second transmitter of two transmitters) the best individuals from the last generation are presented from all 15 runs for determination of transmitter optimal location and power for all seven cases and for the minimal strength of the electric field $E_{1 \mathrm{~min}}=0.1 \mathrm{~V} / \mathrm{m}$ and $E_{2 \min }=0.5 \mathrm{~V} / \mathrm{m}$. In Table 6 (for first transmitter of three transmitters), Table 7 (for second transmitter of three transmitters) and Table 8 (for third transmitter of three transmitters) the best individuals from last generation are presented from all 15 runs for determination of transmitter optimal location and power for all seven cases and for the minimal strength of the electric field $E_{1 \min }=0.1 \mathrm{~V} / \mathrm{m}, E_{2 \min }=0.1 \mathrm{~V} / \mathrm{m}$ and $E_{3 \min }=0.1 \mathrm{~V} / \mathrm{m}$. In Table 9 (for first transmitter of three transmitters), Table 10 (for second transmitter of three transmitters) and Table 11 (for third transmitter of three transmitters) the best individuals from last generation are presented from all 15 runs for determination of transmitter optimal location and power for all seven cases and for the minimal strength of the electric field $\mathrm{E}_{1 \min }=0.1 \mathrm{~V} / \mathrm{m}, \mathrm{E}_{2 \min }=0.5 \mathrm{~V} / \mathrm{m}$ and $\mathrm{E}_{3 \mathrm{~min}}=1.0 \mathrm{~V} / \mathrm{m}$.

\begin{tabular}{|l|l|l|l|}
\hline Case & $\mathrm{ERP}_{1}(\mathrm{dBW})$ & $\mathrm{x}_{\mathrm{cl}}(\mathrm{m})$ & $\mathrm{y}_{\mathrm{cl}}(\mathrm{m})$ \\
\hline $1^{\text {st }}$ & 6.31 & 103.77 & 97.68 \\
\hline $2^{\text {nd }}$ & 6.45 & 99.29 & 96.35 \\
\hline $3^{\text {rd }}$ & 6.72 & 96.83 & 87.78 \\
\hline $4^{\text {th }}$ & 6.17 & 99.68 & 100.75 \\
\hline $5^{\text {th }}$ & 6.70 & 103.90 & 103.71 \\
\hline $6^{\text {th }}$ & 6.91 & 99.77 & 102.29 \\
\hline $7^{\text {th }}$ & 6.52 & 102.75 & 104.68 \\
\hline
\end{tabular}

Tab. 2. The best individuals from the last generation from all 15 runs for all 7 cases and for the minimal strength of the electric field $\mathrm{E}_{1 \mathrm{~min}}=0.1 \mathrm{~V} / \mathrm{m}$ (for $1^{\text {st }}$ transmitter)

\begin{tabular}{|l|l|l|l|}
\hline Case & $\mathrm{ERP}_{2}(\mathrm{dBW})$ & $\mathrm{x}_{\mathrm{c} 2}(\mathrm{~m})$ & $\mathrm{y}_{\mathrm{c} 2}(\mathrm{~m})$ \\
\hline $1^{\text {st }}$ & 6.53 & 103.72 & 97.67 \\
\hline $2^{\text {nd }}$ & 6.49 & 99.30 & 96.48 \\
\hline $3^{\text {rd }}$ & 7.13 & 94.91 & 84.98 \\
\hline $4^{\text {th }}$ & 6.49 & 99.84 & 100.23 \\
\hline $5^{\text {th }}$ & 6.44 & 101.21 & 101.48 \\
\hline $6^{\text {th }}$ & 6.17 & 99.67 & 102.26 \\
\hline $7^{\text {th }}$ & 6.65 & 99.78 & 101.68 \\
\hline
\end{tabular}

Tab. 3. The best individuals from the last generation from all 15 runs for all 7 cases and for the minimal strength of the electric field $\mathrm{E}_{2 \mathrm{~min}}=0.1 \mathrm{~V} / \mathrm{m}$ (for $2^{\text {nd }}$ transmitter) 


\begin{tabular}{|l|l|l|l|}
\hline Case & $\mathrm{ERP}_{1}(\mathrm{dBW})$ & $\mathrm{x}_{\mathrm{c} 1}(\mathrm{~m})$ & $\mathrm{y}_{\mathrm{c} 1}(\mathrm{~m})$ \\
\hline $1^{\text {st }}$ & 6.86 & 97.59 & 90.60 \\
\hline $2^{\text {nd }}$ & 6.27 & 99.64 & 101.19 \\
\hline $3^{\text {rd }}$ & 7.18 & 101.04 & 119.09 \\
\hline $4^{\text {th }}$ & 6.77 & 102.26 & 98.09 \\
\hline $5^{\text {th }}$ & 6.91 & 101.86 & 97.43 \\
\hline $6^{\text {th }}$ & 6.71 & 90.73 & 105.47 \\
\hline $7^{\text {th }}$ & 7.50 & 92.78 & 99.48 \\
\hline
\end{tabular}

Tab. 4. The best individuals from the last generation from all 15 runs for all 7 cases and for minimal strength of electric field $\mathrm{E}_{1 \mathrm{~min}}=0.1 \mathrm{~V} / \mathrm{m}$ (for $1^{\mathrm{st}}$ transmitter)

\begin{tabular}{|l|l|l|l|}
\hline Case & $\mathrm{ERP}_{2}(\mathrm{dBW})$ & $\mathrm{x}_{\mathrm{c} 2}(\mathrm{~m})$ & $\mathrm{y}_{\mathrm{c} 2}(\mathrm{~m})$ \\
\hline $1^{\text {st }}$ & 20.09 & 100.88 & 99.98 \\
\hline $2^{\text {nd }}$ & 20.05 & 99.99 & 99.93 \\
\hline $3^{\text {rd }}$ & 20.82 & 99.75 & 118.02 \\
\hline $4^{\text {th }}$ & 20.06 & 99.90 & 99.95 \\
\hline $5^{\text {th }}$ & 20.08 & 100.61 & 99.81 \\
\hline $6^{\text {th }}$ & 20.37 & 100.07 & 107.67 \\
\hline $7^{\text {th }}$ & 20.39 & 91.85 & 100.00 \\
\hline
\end{tabular}

Tab. 5. The best individuals from the last generation from all 15 runs for all 7 cases and for minimal strength of electric field $\mathrm{E}_{2 \min }=0.5 \mathrm{~V} / \mathrm{m}$ (for $2^{\text {nd }}$ transmitter)

\begin{tabular}{|l|l|l|l|}
\hline Case & $\mathrm{ERP}_{1}(\mathrm{dBW})$ & $\mathrm{x}_{\mathrm{c} 1}(\mathrm{~m})$ & $\mathrm{y}_{\mathrm{c} 1}(\mathrm{~m})$ \\
\hline $1^{\text {st }}$ & 7.04 & 115.14 & 95.70 \\
\hline $2^{\text {nd }}$ & 7.30 & 101.72 & 100.02 \\
\hline $3^{\text {rd }}$ & 6.70 & 100.93 & 86.41 \\
\hline $4^{\text {th }}$ & 6.54 & 108.60 & 102.97 \\
\hline $5^{\text {th }}$ & 6.41 & 96.24 & 97.74 \\
\hline $6^{\text {th }}$ & 7.08 & 96.37 & 118.81 \\
\hline $7^{\text {th }}$ & 6.50 & 93.99 & 96.84 \\
\hline
\end{tabular}

Tab. 6. The best individuals from the last generation from all 15 runs for all 7 cases and for minimal strength of electric field $\mathrm{E}_{1 \mathrm{~min}}=0.1 \mathrm{~V} / \mathrm{m}$ (for $1^{\text {st }}$ transmitter)

\begin{tabular}{|l|l|l|l|}
\hline Case & $\mathrm{ERP}_{2}(\mathrm{dBW})$ & $\mathrm{x}_{\mathrm{c} 2}(\mathrm{~m})$ & $\mathrm{y}_{\mathrm{c} 2}(\mathrm{~m})$ \\
\hline $1^{\text {st }}$ & 6.78 & 116.28 & 99.39 \\
\hline $2^{\text {nd }}$ & 6.89 & 99.60 & 102.48 \\
\hline $3^{\text {rd }}$ & 6.86 & 114.59 & 95.39 \\
\hline $4^{\text {th }}$ & 7.17 & 102.82 & 109.16 \\
\hline $5^{\text {th }}$ & 7.18 & 91.24 & 103.80 \\
\hline $6^{\text {th }}$ & 6.83 & 101.32 & 110.54 \\
\hline $7^{\text {th }}$ & 6.88 & 87.10 & 105.96 \\
\hline
\end{tabular}

Tab. 7. The best individuals from the last generation from all 15 runs for all 7 cases and for minimal strength of electric field $\mathrm{E}_{2 \min }=0.1 \mathrm{~V} / \mathrm{m}$ (for $2^{\text {nd }}$ transmitter) 
Rolich, T. \& Grundler, D.: GA Aided Optimization of Transmitters' Parameters to ...

\begin{tabular}{|l|l|l|l|}
\hline Case & $\mathrm{ERP}_{3}(\mathrm{dBW})$ & $\mathrm{x}_{\mathrm{c} 3}(\mathrm{~m})$ & $\mathrm{y}_{\mathrm{c} 3}(\mathrm{~m})$ \\
\hline $1^{\text {st }}$ & 6.58 & 107.36 & 101.34 \\
\hline $2^{\text {nd }}$ & 6.79 & 102.36 & 106.44 \\
\hline $3^{\text {rd }}$ & 6.85 & 98.25 & 82.99 \\
\hline $4^{\text {th }}$ & 6.26 & 103.56 & 98.87 \\
\hline $5^{\text {th }}$ & 6.78 & 105.94 & 98.05 \\
\hline $6^{\text {th }}$ & 7.43 & 95.58 & 114.73 \\
\hline $7^{\text {th }}$ & 7.90 & 86.53 & 94.49 \\
\hline
\end{tabular}

Tab. 8. The best individuals from the last generation from all 15 runs for all 7 cases and for minimal strength of electric field $\mathrm{E}_{3 \min }=0.1 \mathrm{~V} / \mathrm{m}$ (for $3^{\text {rd }}$ transmitter)

\begin{tabular}{|l|l|l|l|}
\hline Case & $\mathrm{ERP}_{1}(\mathrm{dBW})$ & $\mathrm{x}_{\mathrm{c} 1}(\mathrm{~m})$ & $\mathrm{y}_{\mathrm{c} 1}(\mathrm{~m})$ \\
\hline $1^{\text {st }}$ & 9.08 & 90.36 & 101.74 \\
\hline $2^{\text {nd }}$ & 9.60 & 105.56 & 95.49 \\
\hline $3^{\text {rd }}$ & 7.92 & 85.00 & 113.98 \\
\hline $4^{\text {th }}$ & 9.88 & 105.29 & 93.08 \\
\hline $5^{\text {th }}$ & 8.52 & 93.28 & 106.48 \\
\hline $6^{\text {th }}$ & 10.25 & 105.64 & 110.91 \\
\hline $7^{\text {th }}$ & 9.46 & 95.36 & 108.68 \\
\hline
\end{tabular}

Tab. 9. The best individuals from the last generation from all 15 runs for all 7 cases and for minimal strength of electric field $\mathrm{E}_{1 \mathrm{~min}}=0.1 \mathrm{~V} / \mathrm{m}$ (for $1^{\text {st }}$ transmitter)

\begin{tabular}{|l|l|l|l|}
\hline Case & $\mathrm{ERP}_{2}(\mathrm{dBW})$ & $\mathrm{x}_{\mathrm{c} 2}(\mathrm{~m})$ & $\mathrm{y}_{\mathrm{c} 2}(\mathrm{~m})$ \\
\hline $1^{\text {st }}$ & 20.36 & 97.16 & 100.28 \\
\hline $2^{\text {nd }}$ & 20.63 & 107.80 & 94.19 \\
\hline $3^{\text {rd }}$ & 21.39 & 94.82 & 74.97 \\
\hline $4^{\text {th }}$ & 20.73 & 108.48 & 93.43 \\
\hline $5^{\text {th }}$ & 20.24 & 101.52 & 99.85 \\
\hline $6^{\text {th }}$ & 20.71 & 90.87 & 104.86 \\
\hline $7^{\text {th }}$ & 20.73 & 91.69 & 105.82 \\
\hline
\end{tabular}

Tab. 10. The best individuals from the last generation from all 15 runs for all 7 cases and for minimal strength of electric field $\mathrm{E}_{2 \min }=0.5 \mathrm{~V} / \mathrm{m}$ (for $2^{\text {nd }}$ transmitter)

\begin{tabular}{|l|l|l|l|}
\hline Case & $\mathrm{ERP}_{3}(\mathrm{dBW})$ & $\mathrm{x}_{\mathrm{c} 3}(\mathrm{~m})$ & $\mathrm{y}_{\mathrm{c} 3}(\mathrm{~m})$ \\
\hline $1^{\text {st }}$ & 26.18 & 99.71 & 97.93 \\
\hline $2^{\text {nd }}$ & 26.70 & 107.23 & 91.94 \\
\hline $3^{\text {rd }}$ & 27.37 & 100.97 & 70.52 \\
\hline $4^{\text {th }}$ & 26.69 & 107.23 & 92.32 \\
\hline $5^{\text {th }}$ & 26.12 & 100.16 & 100.81 \\
\hline $6^{\text {th }}$ & 27.72 & 100.18 & 61.84 \\
\hline $7^{\text {th }}$ & 27.74 & 100.00 & 60.94 \\
\hline
\end{tabular}

Tab. 11. The best individuals from last generation from all 15 runs for all 7 cases and for minimal strength of electric field $\mathrm{E}_{3 \mathrm{~min}}=1.0 \mathrm{~V} / \mathrm{m}$ (for $3^{\text {rd }}$ transmitter) 
Comparing results from Tables 2 and 3 and Tables 4 and 5 for different minimal strength of the electric field it can be concluded that in case of higher value of minimal strength of the electric field higher ERP (effectively isotropic radiated power in respect to half-wave dipole) is needed. Because of that, the area of transmitter location is more limited (transmitter must be placed further away from protected areas). Similar can be concluded for cases of three transmitters from results presented in Table 6, 7 and 8 and Tables 9, 10 and 11 .

Fig. 1. presents observing area, protected areas and valid transmitters positions for two cases for the maximal strength of the electric field $E_{\max }=10 \mathrm{~V} / \mathrm{m}$ and minimal strength of the electric field $\mathrm{E}_{1 \min }=0.1 \mathrm{~V} / \mathrm{m}, \mathrm{E}_{2 \min }=0.1 \mathrm{~V} / \mathrm{m}$ (for two transmitters). Possible transmitters' positions for first transmitter are marked with light gray circles, and possible transmitters' positions for second transmitter are marked with dark gray circles. Fig. 2. presents observing area, protected areas and valid transmitters positions for two cases for maximal strength of the electric field $E_{\max }=10 \mathrm{~V} / \mathrm{m}$ and minimal strength of the electric field $E_{1 \min }=0.1 \mathrm{~V} / \mathrm{m}$ and $E_{2 \min }=0.5 \mathrm{~V} / \mathrm{m}$ (for two transmitters). Fig. 3. presents observing area, protected areas and valid transmitters positions for two cases for maximal strength of the electric field $E_{\max }=10 \mathrm{~V} / \mathrm{m}$ and minimal strength of the electric field $E_{1 \min }=E_{2 \min }=E_{3 \min }=0.1 \mathrm{~V} / \mathrm{m}$. Possible transmitters' positions for first transmitter are marked with medium gray circles, possible transmitters' positions for second transmitter are marked with dark gray circles and possible transmitters' positions for third transmitter are marked with light gray circles. Fig. 4. presents observing area, protected areas and valid transmitters positions for two cases for maximal strength of the electric field $E_{\max }=10 \mathrm{~V} / \mathrm{m}$ and minimal strength of the electric field $\mathrm{E}_{1 \min }=0.1 \mathrm{~V} / \mathrm{m}, \mathrm{E}_{2 \min }=0.5 \mathrm{~V} / \mathrm{m}$ and $\mathrm{E}_{3 \min }=1.0$ $\mathrm{V} / \mathrm{m}$.

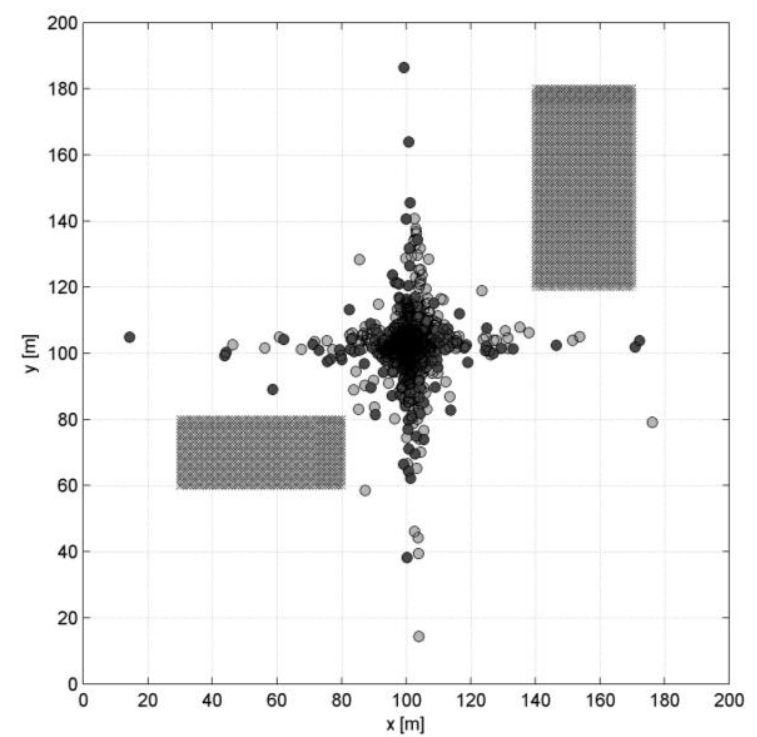

a. $5^{\text {th }}$ case

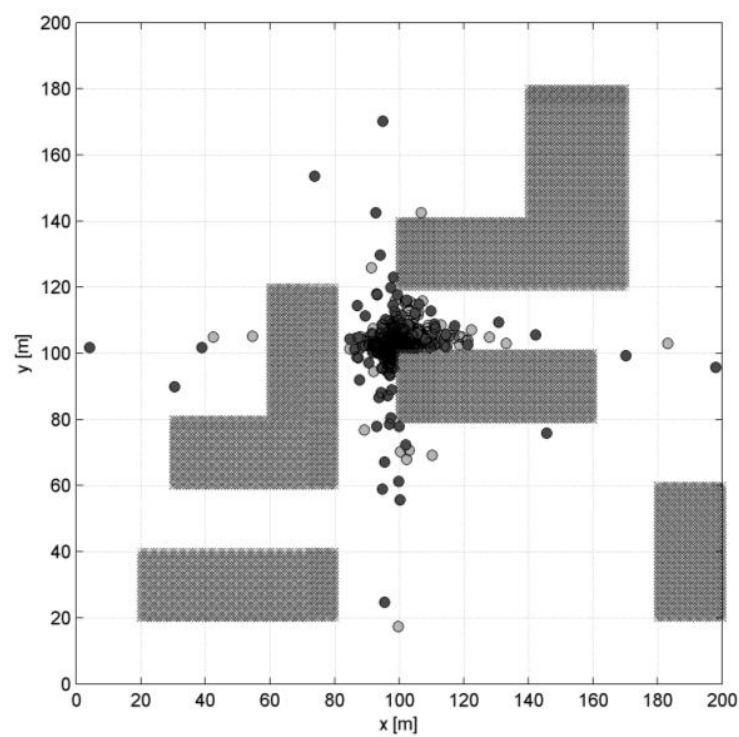

b. $7^{\text {th }}$ case

Fig. 1. Valid transmitters' positions from last generation for two cases, maximal strength of the electric field $E_{\max }=10 \mathrm{~V} / \mathrm{m}$ and minimal strength of the electric field $\mathrm{E}_{1 \min }=\mathrm{E}_{2 \min }=0.1 \mathrm{~V} / \mathrm{m}$ 
Rolich, T. \& Grundler, D.: GA Aided Optimization of Transmitters' Parameters to ...

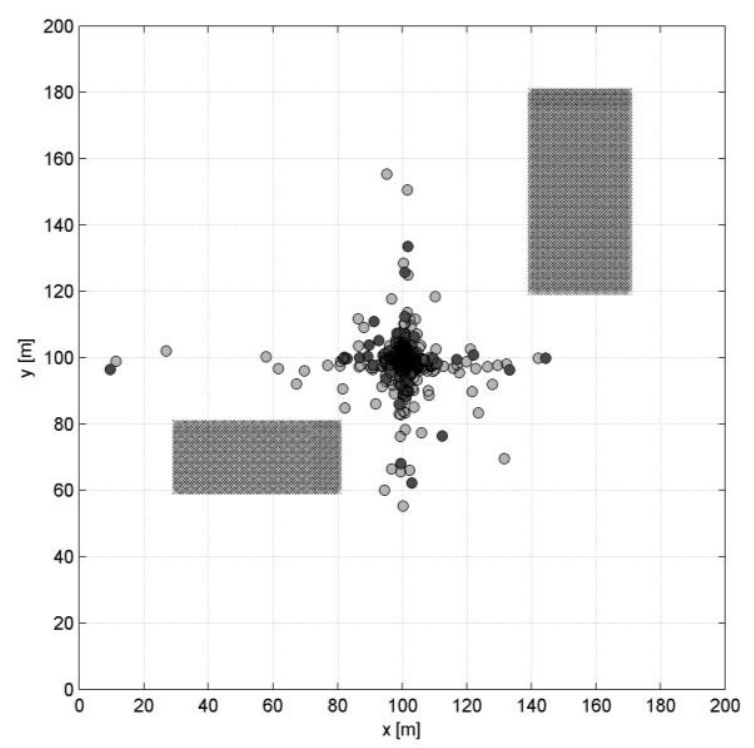

a. $5^{\text {th }}$ case

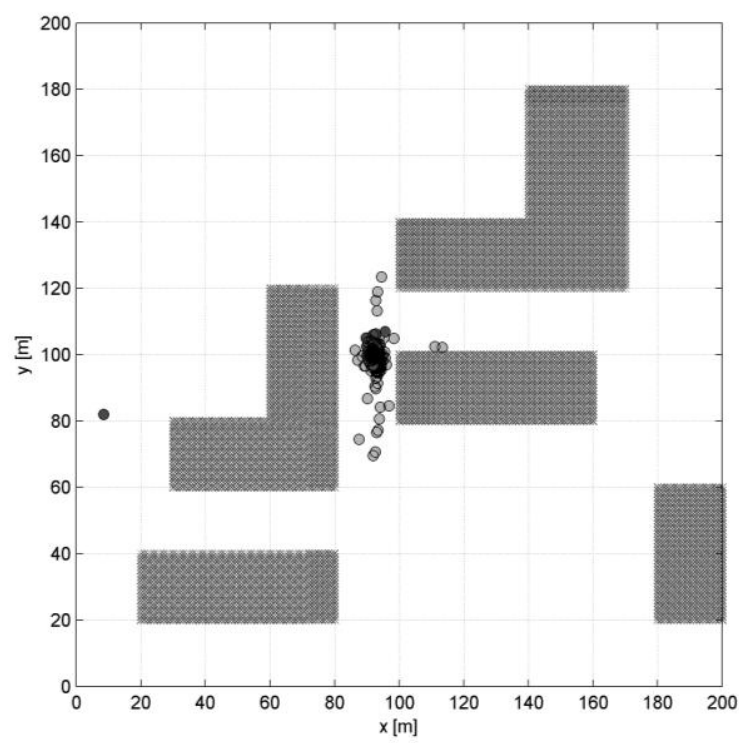

b. $7^{\text {th }}$ case

Fig. 2. Valid transmitters' positions from last generation for two cases, maximal strength of the electric field $E_{\max }=10 \mathrm{~V} / \mathrm{m}$ and minimal strength of the electric field $\mathrm{E}_{1 \min }=0.1 \mathrm{~V} / \mathrm{m}$ and $\mathrm{E}_{2 \min }=0.5 \mathrm{~V} / \mathrm{m}$

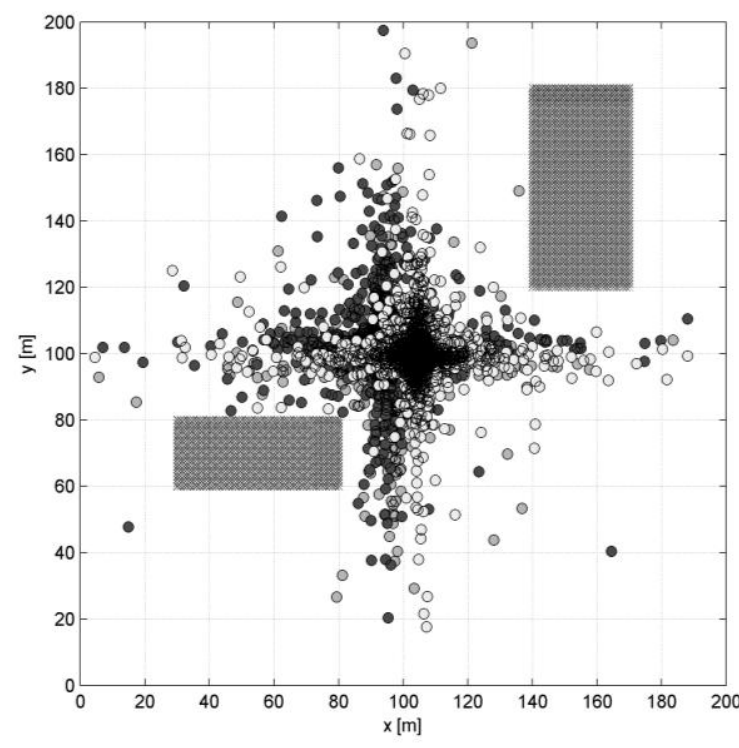

a. $5^{\text {th }}$ case

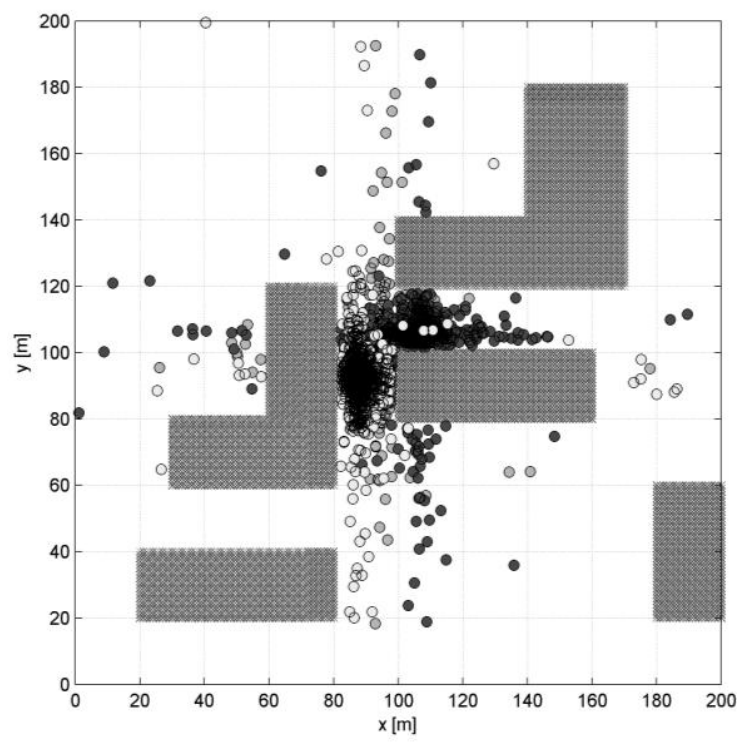

b. $7^{\text {th }}$ case

Fig. 3. Valid transmitters' positions from last generation for two cases, maximal strength of the electric field $\mathrm{E}_{\max }=10 \mathrm{~V} / \mathrm{m}$ and minimal strength of the electric field $\mathrm{E}_{1 \min }=\mathrm{E}_{2 \min }=\mathrm{E}_{3 \min }=0.1 \mathrm{~V} / \mathrm{m}$ 


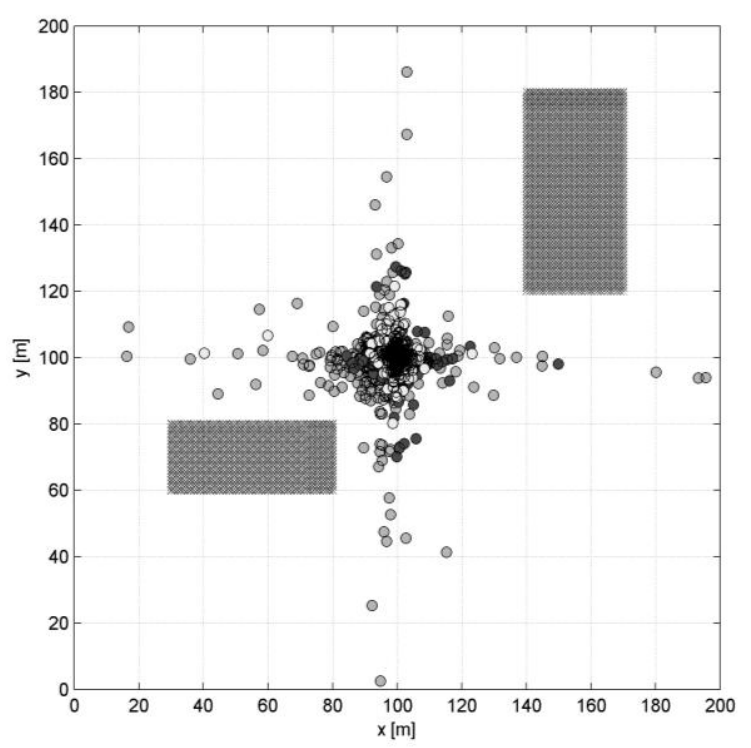

a. $5^{\text {th }}$ case

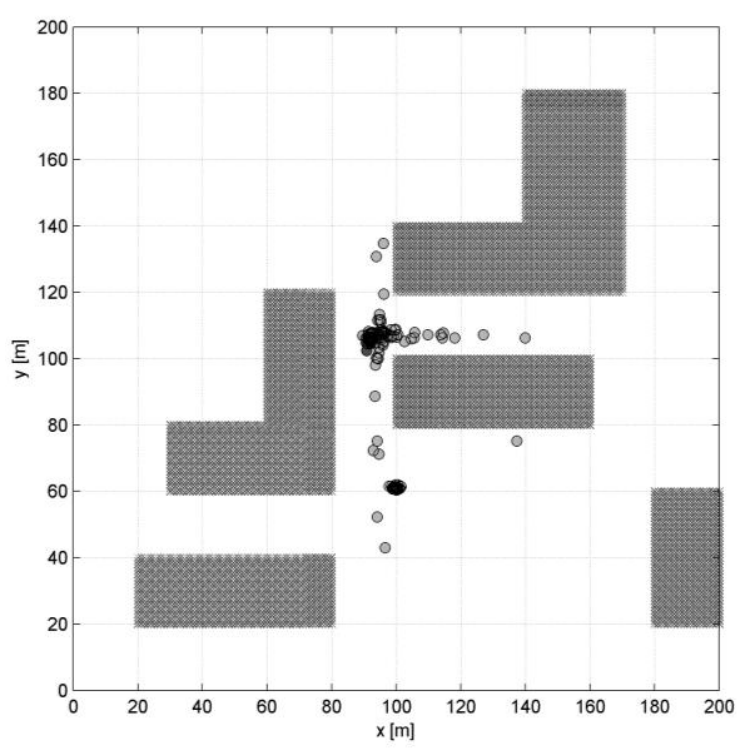

b. $7^{\text {th }}$ case

Fig. 4. Valid transmitters' positions from last generation for two cases, maximal strength of the electric field $E_{\max }=10 \mathrm{~V} / \mathrm{m}$ and minimal strength of the electric field $\mathrm{E}_{1 \min }=0.1 \mathrm{~V} / \mathrm{m}, \mathrm{E}_{2 \min }=0.5 \mathrm{~V} / \mathrm{m}$ and $\mathrm{E}_{3 \min }=1.0 \mathrm{~V} / \mathrm{m}$

\section{Conclusion}

Based on presented results it can be concluded that the genetic algorithm can be applied for determining optimal transmitter location and power in observed area satisfying certain criteria. Although in this investigation is optimized for one, two and three transmitters locations and powers and the electric field is in plane, based on results it can be assumed that method is applicable for complex cases. The arithmetic mean value of fitness function decreases with number of generations while the fitness function of the best individual is practically the same. The reason for that is holding the best individual through generations (an elitist type of genetic algorithm). The genetic algorithm finds set of solutions which satisfy defined requirements (conditions) and have favourable fitness function value in case that transmitter could not be placed in location determined by the best individual.

In further investigations method will be used for determining optimal locations and powers for transmitters which do not have uniform distribution of radiation and for three dimensional spaces.

\section{References}

He, J.; et al. (2002). Global optimization of transmitter placement in wireless communication systems, Proceedings High Performance Computing Symposium 2002, Sahni, S.; Prasanna, K.V.; Shukla, U. (Eds.), pp. 328-333, ISBN 3-540-00303-7, Bangalore, India, December 2002, Springer, Berlin Heidelberg 
Rolich, T. \& Grundler, D.: GA Aided Optimization of Transmitters' Parameters to ...

Lin, B.; Ho, P.-H.; Xie, L.-L. \& Shen, X. S. (2007). Optimal Relay Station Placement in IEEE 802.16j Networks, Proceedings of the 2007 international conference on Wireless communications and mobile computing (IWCMC), pp. 25-30, ISBN 978-1-59593-695-0, Honolulu, Hawaii, USA

Mendes, S. P.; et al. (2006). A Differential Evolution Based Algorithm to Optimize the Radio Network Design Problem, Proceedings of the Second IEEE International Conference on e-Science and Grid Computing, pp. 119-124, ISBN 0-7695-2734-5, IEEE Computer Society Washington, DC, USA

Poljak, D. (2006). People's exposure to non-ionizing radiation, Kigen d.o.o., ISBN 953-6970-25-2, Zagreb, (in Croatian)

Sakthivel, S. \& Suresh, R. (2006). A Genetic Algorithm Approach to Solve Mobile Base Station Location Problem. International Journal of Soft Computing, Vol. 1, No. 3, pp. 160-165, ISSN 1816-9503 